\title{
Attitudes Toward Smartphone Characteristics: What Do Users Pay For?
}

\author{
https://doi.org/10.3991/ijim.v14i09.13089 \\ Maral Jamalova ( $\left.{ }^{\bowtie}\right)$, Milán György Constantinovits \\ Szent István University, Gödöllő, Hungary \\ mjamalova@hotmail. com
}

\begin{abstract}
This paper examines attitudes towards smartphone characteristics (features, functions and relative advantage indicators) from the users' perspective. A questionnaire survey was conducted among smartphone users $(n=486)$ from different countries, however, most of the respondents were Azerbaijanis or Hungarians. The results of the survey were analyzed using Principal Component Analysis which enables to group the most important variables based on their correlations. Six components were extracted and $65 \%$ of the total variance was explained by the components. Surprisingly, Personal Digital Assistant tasks and Technical Features seem to be more important for smartphone users than Relative Advantage indicators (i.e. including the price of the handset). The main purpose of the mobile/smartphones - being in touch - explains less than seven percent of the total variance. Afterward, the respondents were clustered in 5 groups according to Rogers' [2003. Diffusion of innovations (5th ed.). New York, NY: Free Press] adopter categories, using the results of PCA for K-means cluster analysis. Based on the output of cluster analysis and final cluster centers, the adopter categories were defined. The results illustrate that the number of innovators and early adopters is significantly high in comparison with the original numbers offered by Rogers.
\end{abstract}

Keywords - Smartphone market, consumer attitudes, adopter categories, smartphone diffusion.

\section{$1 \quad$ Introduction}

In the book called "Digital convergence-libraries of the future", the authors defined a smartphone as "a phone that uses an open operating system that allows for the installation of natively-coded software" [1, p. 273]. The smartphone is the result of product improvement and technology development launched by analog mobile phone producers. It is a highly innovative product [2], however, success in the market and high sales depend on technical features and characteristics [3] in combination with branding [4], design [5] and price [6], [7] and so on. Nowadays, the cheap price of the handsets [8], and the necessity of being in touch (basically in the context of developing countries [9]) made the small device an irreplaceable part of everyday life of each individual. As a result of product development as well as vendors' sales strategy [10] smartphones were 
packed with additional features [11]. The handsets combine multiple functions as a communication tool, the device for controlling e-mails, social media, health conditions, bank transactions and other necessary information [12]. The smartphone became an irreplaceable tool which lets individuals be online and organize daily activities. The average lifespan of smartphones is until 3 years [13], however, it can be subject to discussion.

The authors of the current paper designed and implemented a questionnaire survey in order to understand buyers' attitudes toward different functions, features and relative advantage indicators to highlight the most important ones. Attitudes toward the product are usually classified as hedonic (i.e. pleasure) and utilitarian while this study is focused only on utilitarian aspects of attitudes. The previous researches in smartphone market included only hedonic [14] and utilitarian attitudes [15], [16] separately, or both of them together [17], [18].

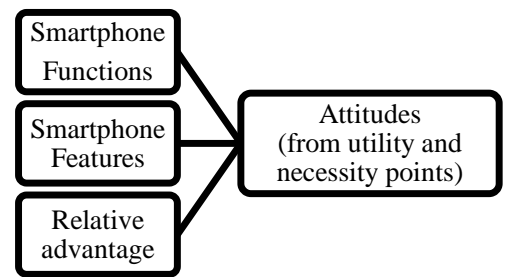

Fig. 1. Attitudes of smartphone users from utility and necessity points of view Source: own editing, 2019

The current research was mainly conducted among Azerbaijani and Hungarian smartphone users ( $88.9 \%$ of total respondents) while there were few representatives of other nations. The authors of this study applied a product-based approach in order to understand the user's attitude toward smartphone and usage intentions. In accordance with the aim of the research, the sample was not divided into subsamples and was analyzed without making any separation. In the smartphone market product-based approach was considered as a combination of basic requirements (i.e. price/quality ratio, compliance with telecommunication standards), physical (i.e. weight, design and etc.) and technical characteristics [19].

Income and education level, unemployment and the other macroeconomic indicators [20], as well as smartphone characteristics, have also a huge impact on the buyers' decisions in the smartphone market [21], [22]. This paper was purposed for filling the gap connected with user attitudes towards smartphone characteristics (i.e. functions and features) without considering geographic differences. However, in the current paper, smartphone characteristics are a combination of smartphone functions, features, and relative advantage indicators. Similar studies were conducted among mobile phone/smartphone users in Turkey and Finland [15], [16]. The topic was not extensively analyzed either in Azerbaijani or in Hungarian case. Moreover, there were limited studies measuring consumer attitudes, and preferences in Azerbaijan and Hungary, and there was almost no any study connected the smartphone market. The originality of this paper is based on several points and these points highlighted as answers to 
research questions. The objectives of the paper are also connected with finding the answers to research questions. The research questions are stated as follows:

1. Which functions and features are more important for smartphone users?

2. If information regarding smartphone characteristics will be summarized, which factors would have more weight?

3. How smartphone users can be classified according to Rogers' adopter categories?

\section{$2 \quad$ Literature Review}

\subsection{Attitudes toward the smartphone characteristics}

Attitude is one of the most complex concepts of consumer psychology and a "fundamental contributor" of an individual's reaction to the surrounding [23, p. 419]. Crano and Prislin (2006) defined the attitudes as "the evaluative judgments that integrate and summarize these cognitive/affective reactions as cited in [24, p. 3]". Simply, the attitudes are the opinions of the customers regarding anything which can be marketed (i.e. like the idea, the product/service). From a consumer behavior perspective, a customer's attitude is important for the researchers as it creates an opportunity to predict behavior (Wanke, 2008, p. 5). So, the results of the present study can be considered as significant for both purchase and usage situations. The smartphone is a complicated device, however, only some of the mentioned capabilities are more essential before purchase and during the usage of the devices. The users' attitudes toward smartphones are the result of conflicting ideas, beliefs, experiences, values and so on. Advertisements, the gender of the consumer/user and usage priorities also might influence attitude toward the product [25].

The importance of different functions and features might be considered from the utility (i.e. the use of functions/features) and the necessity (i.e. the importance of functions/features) sides [26]. In order to identify individuals' loyalty in the Korean smartphone market, M. K Kim [7] defined 5 attributes of smartphones. These attributes are "functions (i.e. physical and functional performance), usability, design, application and price" [7, p. 939]. Moreover, the variables as "product features, brand name, product price, and social influence" were chosen for measuring the impact of different factors on students' smartphones choice in Malaysia [27, p. 237]. In the mentioned study, the product features included design, variety of applications and games, access to the Internet, and operating system [27]. However, the other researchers underlined "price, after-sales service, brand, social influence, durability, and product features" [21, p. 105] as essential factors influencing users'/buyers' purchase behavior. Overall, based on the above-mentioned researches, a mobile phone/smartphone purchase build upon on attributes as functions/features (including design, OS, applications and the other parameters), brand, price and social influence. These attributes formulate users' attitudes toward the smartphone. All attributes were considered in the current research aimed to measure users' attitudes toward the handsets. 


\subsection{The influence of smartphone characteristics on purchase and usage behaviour}

In the case of smartphones, physical characteristics are as important as technological capabilities. Aesthetics/design [6], [28] or so-called "style features" such as colors, size, etc. [29] have a strong influence on buyers choice [5]. Numerous studies [5], [19], [28] measured users' attitudes towards smartphone design. According to the research conducted among Chinese smartphone users [30] by applying Technology Acceptance Model (TAM), physical characteristics, and design can be considered to be one of the important factors of smartphone acceptance and use. The other study investigated the importance of design in smartphone usage from affordance point [2] through Innovation Diffusion Theory (IDT) and the result of the analysis for relative advantage solely were significant. Consequently, the smartphone design is one of the important attributes of buyers/users purchase and usage decision.

However, technical characteristics of handsets [31] and applications [32] are also very important for smartphone owners. Technical characteristics of smartphones as well as operating system improvement can be considered influential for entire product category [31]. As result, nowadays smartphone owners well informed about camera features [33], fingerprint [34] and so on.

\subsection{Relative advantage as an indicator of smartphone diffusion}

In the case of the mobile phone/smartphone market, the application of innovations and perceived innovativeness of the device play a crucial role in purchase and usage behavior [35] [37]. From the marketing perspective, the theories related to innovation adoption create the foundation to investigate and develop concepts related to purchasing behavior and adopter categories [38].

The authors of this paper considered Innovation Diffusion Theory (IDT) offered by E. Rogers [35] as more appropriate for application on the smartphone market. Rogers differentiated five main attributes of perceived innovativeness: relative advantage, compatibility, complexity, trialability, and observability [35, p. 262]. Some studies proved the compliance of IDT for explanation smartphone usage [2], [39], furthermore, the importance of IDT and interconnection between attitudes and innovation diffusion indicators were also investigated [2]. However, the researchers [2], [39] considered only relative advantage as being important from a device characteristic perspective. Hence, only Relative Advantage was included in the study.

\subsection{Diffusion theories and adopter categories}

Marketing and innovation literature examine the adoption of innovative products from two different approaches. The first and the traditional approach includes when scientists try to make forecasts about a newly marketed product, and its adoption [40], [41]. The other researchers are interested in innovations which are the part of the product improvement in the case of already existing high-tech product [42], [43]. The most cited researches related to innovation diffusion and adopter categories were published 
by Rogers [35], [44], and Bass [45]. The first book of E. Rogers regarding IDT was published in 1962 where he offered to measure innovativeness based on the standard deviation of the average time of innovation adoption. Later, Bass [45] developed and improved the mathematical side of diffusion theory offered by Rogers.

The authors of the current paper assume, that, even if mentioned approaches are totally different from an enterprise, innovation management, and product improvement perspective, buyers' personality, psychology, values, attitude toward innovations, etc. are the same. So, it would not be a mistake to classify smartphone buyers according to adopter categories which are oriented basically to new product diffusion. Moreover, there are studies [46] [48] examining adopter categories in the smartphone market however scientists tend to use different classifications of the adopters. For example, Kim et al. [46] divided smartphone adopters into the groups of current adopters, potential adopters, and non-adopters. The other authors examined the adoption and the diffusion of mobile devices among students by applying Technology Adopter Category Index [47]. Also, the use of smartphones during travel by applying Rogers' adopter categories was investigated [48].

\section{$3 \quad$ Methodology}

\subsection{Participants}

The study focuses on smartphone users from Hungary and Azerbaijan. The survey was conducted by spreading out a questionnaire over social media in four different languages (i.e. Azerbaijani, Hungarian, Russian and English). Responses were collected during a month, from March 20 to April 20, 2019. Participants were mainly from Azerbaijan and Hungary, however, some respondents from other countries also filled the questionnaire. So, it made possible to gain more information about the necessary features, functions, and parameters of smartphones.

According to the demographic profile of respondents, more than $70 \%$ of the individuals are younger than 35 . Also, about $80 \%$ of the survey participants have bachelor's or master's degree. Moreover, around $15 \%$ of the respondents filled the questionnaire in English. Among the survey participants, 38\% of respondents used Samsung, $26 \%$ of Apple smartphones. Only $12 \%$ of smartphone owners choose Xiaomi or Huawei smartphones. (See Table 1.)

\subsection{Procedures}

Participants were asked to fill the online self-completion questionnaire. The purpose of the questionnaire survey was to understand and identify smartphone users' attitude toward the device characteristics and utility. Based on the research purpose, the questions were grouped in three categories: features, functions, and relative advantage. The categories are the consequences of several conducted interviews and were created in accordance with smartphone users' opinions. Complicated terms or expressions were 
not included in the research, the main approach was to build a simple, understandable questionnaire and avoid respondents' confusion.

\subsection{Instrument and measures}

The structure of the questionnaire was adopted from the study (multi-criteria decision-making approach) conducted by G. Işıklar and G. Büyüközkan [15] in order to understand the preferred characteristics of young adults in Turkey. Later, the same tool was used for identifying the mobile phone feature preferences of males in Finland [16]. The questionnaire included 22 self-reporting questions related to smartphone use and the necessary information about demographics. The questions were structured in fivepoint Likert scale varying between "not important at all" (1) and "very important" (5) and it is compatible with the previous studies [15], [16].

\subsection{Data collection and respondents' general demographic information}

According to the aim of the research, the questionnaire was distributed by social media mainly approaching users thought Facebook. Around $78 \%$ of the surveyed smartphone owners fell into the 18-34 age category, and only $12 \%$ of the respondents were 34-44 years old (Table 1). Other age groups were represented with a relatively small proportion. The female participants constituted around sixty percent of interviewees. Also, a large proportion of respondents had a bachelor's or a master's degree. The percentage of Azerbaijani survey participants were slightly higher than the Hungarians. The ratio of other nations represented in a survey was relatively small. Basically, the Azeri and Hungarian respondents filled the questionnaire in their mother tongue. The detailed description of the demographic profile is given in Table 1.

\subsection{Sample}

Smartphones have already become an irreplaceable part of individuals' every-day life. So, it was not hard to reach the users and ask them some questions related to the characteristics of the device. The data from the questionnaire surveys are subjective and therefore the selection of respondents can have a significant influence on the survey results [49]. The questionnaire was spread out in several Facebook groups and it was reachable for a large number of smartphone users. Using social media in order to reach consumers/users is not a new approach in marketing [50], [51]. Scientists chose the mentioned way as it is more time-efficient and lets us reach different layers of society. 
Table 1. The demographic profile of the respondents

\begin{tabular}{|c|c|c|c|}
\hline Demographic Variables & Scale & Frequency & Percentage \\
\hline \multirow{6}{*}{ Age of respondent } & $>18$ & 12 & 2.5 \\
\hline & $18-24$ & 120 & 24.7 \\
\hline & $25-34$ & 256 & 52.7 \\
\hline & $35-44$ & 58 & 11.9 \\
\hline & $45-54$ & 26 & 5.3 \\
\hline & $55-64$ & 14 & 2.9 \\
\hline \multirow{2}{*}{ Gender of respondent } & Female & 286 & 58.8 \\
\hline & Male & 200 & 41.2 \\
\hline \multirow{6}{*}{ Qualification of respondent } & Bachelor's degree & 178 & 36.6 \\
\hline & Elementary school & 8 & 1.6 \\
\hline & Master's degree & 194 & 39.9 \\
\hline & Ph.D. candidate or Ph.D. & 30 & 6.2 \\
\hline & Secondary grammar school & 52 & 10.7 \\
\hline & Secondary technical school & 24 & 4.9 \\
\hline \multirow{4}{*}{ Nationality * } & Azerbaijani & 220 & 45.3 \\
\hline & Hungarian & 212 & 43.6 \\
\hline & Russian & 12 & 2.5 \\
\hline & Turkish & 8 & 1.6 \\
\hline \multirow{4}{*}{ Language } & Azeri & 162 & 33.3 \\
\hline & English & 74 & 15.2 \\
\hline & Hungarian & 208 & 42.8 \\
\hline & Russian & 42 & 8.6 \\
\hline \multirow{5}{*}{ Smartphone manufacturer } & Apple & 188 & $38 \%$ \\
\hline & Huawei & 58 & $12 \%$ \\
\hline & Samsung & 130 & $26 \%$ \\
\hline & Xiaomi & 60 & $12 \%$ \\
\hline & Other & 58 & $12 \%$ \\
\hline
\end{tabular}

Note: Nationalities as Chinese, Kazakh, Kyrgyz, Mongolian and Syrian were represented with $0.8 \%$ (4 persons), while Cambodia, Iran, Iraq, Israel, Morocco, Pakistan, Saudi Arabia had only a few respondents $(0.4 \%$ or 2 persons). Source: own editing based on descriptive statistics.

\subsection{Reliability and validity}

The first group (i.e. four variables) were adapted from the fifth edition of "Innovation Diffusion" book. The variables expressing relative advantage were shown as a part of Innovation Diffusion Theory (IDT) together with compatibility, complexity, trialability, and observability [35, p. 52].

The second and the third scales included nine and ten questions respectively. The scales were adapted from the study built on the multi-criteria decision-making approach, aimed to examine mobile phone choice based on the preferred characteristics/options [15], [16]. The research was conducted among young mobile phone users in Turkey in 2007. The authors [15] involved in the research not only smartphone characteristics currently grouped as Features and Functions but also a brand from a marketing perspective. Later, Haverila [16] included the new variables as price and design (separately from aesthetics) which created a more clear picture of mobile phone 
purchases. The authors of the current paper included three new indicators, as innovativeness, satisfaction (later deleted from analysis) and social prestige in order to be able to find an answer to the last research question.

For the sake of identifying the reliability of the questionnaire, each group of variables was tested using Cronbach's alpha. The results of the reliability test were shown in Table 2. The level of alpha for reliability test was accepted to be greater than 0.7 and/or 0.8 in social science [52], [53]. The results of Cronbach's alpha for the first question group was only 0.754 , while the second $(\alpha=0.846)$ and the third groups showed higher rates $(\alpha=0.829)$. All questions were focused on the identification of the important characteristics and users' attitudes [15], [16].

\subsection{Analysis}

The aim of the paper was to group device characteristics and create components showing the attitudes toward smartphone diffusion and adoption. Principal Component Analysis (PCA) is a well-known practical tool measuring linear components in the database [52] and it was chosen as the instrument of dimension reduction. After defining key components of purchase or usage behavior, K-means cluster analysis was applied. The analysis intended to classify the respondents into 5 groups (innovators, early adopters, early majority, late majority, and laggards) according to the segmentation offered by E. Rogers [35] and compare the results with the previous researches.

Table 2. Measurements and reliability

\begin{tabular}{|c|c|}
\hline Concept & Scale estimate \\
\hline \multirow{5}{*}{$\begin{array}{l}\text { "Relative advantage" } \\
\text { adapted from }[34, p . \\
51] \text { Alpha }=0.754\end{array}$} & How important is the brand of a smartphone for you? \\
\hline & How important is the design of a smartphone for you? \\
\hline & $\begin{array}{l}\text { How important is the innovativeness of a smartphone for you? } \\
\text { (e.g. features as fingerprint usage, photographing) }\end{array}$ \\
\hline & To what level are you satisfied with your smartphone? \\
\hline & How important is the social prestige of a smartphone for you? \\
\hline \multirow{9}{*}{$\begin{array}{l}\text { Multi-item measure- } \\
\text { ment: "Features" Al- } \\
\text { pha }=0.846\end{array}$} & How important is the screen size of a smartphone for you? \\
\hline & How important is the weight of a smartphone for you? \\
\hline & How important is the standby time of a smartphone for you? \\
\hline & How important is the talking time of a smartphone for you? \\
\hline & How important are the ports, compatibility to other devices? \\
\hline & How important is the internal memory of a smartphone for you? \\
\hline & How important is the external memory expandability of a smartphone for you? \\
\hline & How important is the camera resolution of a smartphone for you? \\
\hline & How important is the assortment of applications of a smartphone for you? \\
\hline \multirow{7}{*}{$\begin{array}{l}\text { Multi-item measure- } \\
\text { ment "Functions" Al- } \\
\text { pha = 0.829 }\end{array}$} & How important are the phone calls for you? \\
\hline & How important are the text messages for you? \\
\hline & How important is the internet browsing for you? \\
\hline & How important is E-mail for you? \\
\hline & How important are social media applications on a smartphone? \\
\hline & How important is a function making photos for you? \\
\hline & How important is a function for making videos? \\
\hline
\end{tabular}




\begin{tabular}{|l|l|}
\hline & How important is listening to music on a smartphone for you? \\
\cline { 2 - 3 } & How important is playing games on a smartphone for you? \\
\cline { 2 - 2 } & How important is for you the MS office applications on a smartphone? \\
\hline
\end{tabular}

Source: own editing based on Cronbach's Alpha

\section{$4 \quad$ Results and Discussion}

\subsection{Principal Component Analysis (PCA)}

PCA is a useful tool for decreasing the number of variables and summarizing factors/components for creating a clear view of the situation. It is one of the popular analysis in marketing and social sciences. PCA requires a big sample size and it is enough to have more than 300 respondents in the analysis if communalities lower than 0.5 will be deleted [54]. The same statistical test (i.e. Principal Component Analysis using Varimax rotation) was already applied by Haverila [16] in order to find out the feature preferences of males in Finland.

The assumption of normality was not violated [52]. The results for Skewness and Kurtosis was in the accepted range [55]. So, all variables included in the analysis considered to be normally distributed. Satisfaction showed low (i.e. less than 30\%) factor loading, consequently, it was deleted from further analysis. The indicator of sampling adequacy (i.e. $\mathrm{KMO}=0.852$ ) was significantly high while the accepted low end is 0.6 [55]. The result of PCA explained $65.4 \%$ of the total variance. Six main components were extracted based on Kaiser-Guttman retention criteria.

The functions such as e-mail (0.767) and internet browsing $(0.72)$ showed the highest weight while listening to the music (0.57) and smartphone standby time (0.522) demonstrated less importance according to the results of the analysis. Overall, more than 15\% of the total variance was explained by this component. Social media and office applications are quite important for smartphone users. In a study from 2011, Haverila also applied Exploratory Factor Analysis (PCA with Varimax rotation) for understanding mobile phone feature preferences. While some variables included in the studies differ, the first component aimed to explain the same purpose - usability in the business.

Technical Features described $14.3 \%$ of the total variance. It included compatibility with other devices, memory and expandability, the assortment of applications and talking time. Compatibility (i.e. The indicator was used in the questionnaire as "Ports, compatibility to other devices".) was mentioned by E. Rogers [35] as one of the important attributes of innovation diffusion. However, in this study, it was applied in order to differentiate $\mathrm{iOS}$ and Android users and to understand their purchase intention. In literature, a lot of sources prove that Androids are easily adopted by individuals [31], [56]. On the other hand, external memory expandability and, simultaneously, an assortment of applications might also be considered to achieve the above-mentioned goal. Everyone is aware of the fact that it is impossible to expand the external memory of smartphones produced by Apple. So, iOS users take an action before or during the purchase, while owners of Androids can make the decision and expand the memory of a smartphone at any time. Moreover, compatibility $(0.722)$ and memory expandability 
(0.695) have the highest loadings while the assortment of applications (0.684) is also important for buyers. Internal memory $(0.614)$ and talking time $(0.578)$ are less significant in comparison with the others. The second factor of the study also fits the second factor of prior studies [15], [16]. The authors of the current study paid more attention to technical features of smartphones in comparison with previous ones [15], [16]. This is the reason that creates a slight difference between the factors of the studies.

Relative Advantage indicators were involved from the above-mentioned book of $\mathrm{E}$. Rogers as the most influential tool of innovation diffusion. The indicators moved together according to the result of the PCA. The output of PCA strengthened the accuracy of the Relative Advantage category and proved its significance from the user perspective. However, as reported by Rogers [35] the concept based on "economic profitability" later expressed in maintaining and/or demonstrating the status (i.e. used by the author of this paper as "social prestige"). Moreover, Relative Advantage can be taken into account as the main way of expressing superiority [35, p. 270].

Interestingly, brand (0.82) and innovativeness (0.673) of the device are influential indicators of the component. Social prestige (0.665) and design (0.64) have less weight in comparison with the above-mentioned indicators, however, all referred indicators are more powerful than the price of the handset. It confirms the well-known notion that smartphone expresses the social status of its owner [18], [57]. The previous studies showed the importance of the price itself [58], in the terms of the value of money [17] and brand [59] in the decision regarding smartphone adoption as one of brand dimensions. In the study regarding Finland and Turkey [15], [16], aesthetics, design, and quality/raw material properties were included in one component while price was the part of the other component. Moreover, brand choice/brand had bigger weight in comparison with physical characteristics/aesthetics in each of studies. Even with significant time difference (i.e. the first study was conducted in 2007, the second in 2011, and the third in 2019) all of the studies proved the notion that price is not the most important indicator neither for young males in Finland, nor for Turkish users, nor for internationals all over the world.

Photo/Camera is the fourth component which explains more than $11 \%$ of the total variance. According to factor/component loadings, smartphone users are more interested in making photos $(0.833)$ and videos $(0.768)$ than camera resolution. Photographing had the strongest weight which means that the smartphone users are more attentive to this feature than the other features belonging to the component. Component loading for camera resolution is only 0.685 . Unfortunately, prior studies did not include these variables, as mentioned technical features were not available then.

Less than $7 \%$ of the total variance was explained by the component named Communication Tool. Two variables (i.e. text messages and phone calls) were included in the component. The factor/component loading of text messages was significantly high (0.861) in comparison with phone calls. It is already supported by some studies [35], [60], [61] which proved lifestyle change. By contrast, prior works in the mobile phone market [15], [16], did not include the mentioned variables in the research.

Game and Entertainment is the last component which explained $6 \%$ of the total variance. A review of the literature also confirmed the essential place of the game and entertainment in mobile phone adoption [15], [16]. Cronbach's Alpha for previous 
components showed quite high results (i.e. around 0.7 or higher), while the last factor had a value below 0.3. The research conducted in Finland [16] had also the same results in terms of the last component related to games. Playing games had the strongest impact $(-0.67)$, however, the score had a negative sign. The other variables were screen size (0.484) and weight (0.608) while weight seems to be more important for smartphone owners.

Table 3. The results of Principal Component Analysis

\begin{tabular}{|c|c|c|c|c|c|c|}
\hline Variables & $\begin{array}{l}\text { 1st com- } \\
\text { ponent }\end{array}$ & $\begin{array}{c}2 \text { nd compo- } \\
\text { nent }\end{array}$ & $\begin{array}{l}\text { 3rd com- } \\
\text { ponent }\end{array}$ & $\begin{array}{c}\text { 4th com- } \\
\text { ponent }\end{array}$ & $\begin{array}{c}\text { 5th com- } \\
\text { ponent }\end{array}$ & $\begin{array}{c}\text { 6th compo- } \\
\text { nent }\end{array}$ \\
\hline \multicolumn{7}{|c|}{ Personal Digital Assistant (15,2\% of total variance explained, eigenvalue $=7.1)$} \\
\hline Function: E-mail & .767 & & & & & \\
\hline Function: Internet browsing & .720 & & & & & \\
\hline Function: Social media & .656 & & & & & \\
\hline Function: Office applications & .614 & & & & & \\
\hline Function: Listening to music & .570 & & & & & \\
\hline Feature: Standby time & .522 & & & & & \\
\hline Cronbach alpha/correlation & .807 & & & & & \\
\hline \multicolumn{7}{|c|}{ Technical Features (14,3\% of total variance explained, eigenvalue $=2.6)$} \\
\hline $\begin{array}{l}\text { Feature: Ports, compatibility to other } \\
\text { devices }\end{array}$ & & .722 & & & & \\
\hline $\begin{array}{l}\text { Feature: External memory expandabil- } \\
\text { ity }\end{array}$ & & .695 & & & & \\
\hline Feature: Assortment of applications & & 684 & & & & \\
\hline Feature: Internal memory & & .614 & & & & \\
\hline Feature: Talking time & & .578 & & & & \\
\hline Cronbach alpha/correlation & & .783 & & & & \\
\hline \multicolumn{7}{|c|}{ Relative Advantage (11,9\% of total variance explained, eigenvalue $=2)$} \\
\hline Brand & & & .820 & & & \\
\hline $\begin{array}{l}\text { Innovativeness (e.g. fingerprint usage, } \\
\text { photographing) }\end{array}$ & & & .673 & & & \\
\hline Prestige & & & .665 & & & \\
\hline Design & & & 640 & & & \\
\hline Smartphone price & & & 609 & & & \\
\hline Cronbach alpha/correlation & & & .754 & & & \\
\hline \multicolumn{7}{|c|}{ Camera/Photographing (11,2\% of total variance explained, eigenvalue $=1.7)$} \\
\hline Function: Making photos & & & & .833 & & \\
\hline Function: Making videos & & & & .768 & & \\
\hline Feature: Camera resolution & & & & .685 & & \\
\hline Cronbach alpha/correlation & & & & .833 & & \\
\hline \multicolumn{7}{|c|}{ Communication Tool (6,8\% of total variance explained, eigenvalue $=1.2)$} \\
\hline Function: Text messages & & & & & .861 & \\
\hline Function: Phone calls & & & & & .685 & \\
\hline Cronbach alpha/correlation & & & & & .688 & \\
\hline \multicolumn{7}{|c|}{ Game and entertainment ( $6 \%$ of total variance explained, eigenvalue $=1.1$ ) } \\
\hline Function: Playing games & & & & & & -.670 \\
\hline Feature: Screen size & & & & & & .484 \\
\hline Feature: Weight & & & & & & .608 \\
\hline
\end{tabular}


Paper-Attitudes Toward Smartphone Characteristics: What Do Users Pay For?

\begin{tabular}{|l|l|l|l|l|l|l|}
\hline Cronbach alpha/correlation* & & & & & & \\
\hline
\end{tabular}

Note: PCA with Varimax rotation; components higher than 0.5 extracted; TVA=65.4\%; KMO=0.852.

\subsection{K- means cluster analysis}

$\mathrm{K}$-means cluster analysis was chosen as a statistical tool in order to find an answer to the last research question. K-means cluster analysis lets the researcher identify the number of clusters and creates an opportunity for illustrating final cluster centers [62, p. 126] for each component created by PCA. All surveyed smartphone users (totally 484 smartphone owners) were divided into five groups based on adopter categories offered by Rogers [35]. As a result, the authors of this paper can determine each adopter group easily by considering final cluster centers of smartphone functions, features, and relative advantage indicators without asking the clarifying questions.

'Innovators' were considered to be the first buyers/users of any newly offered product or service. The distinctiveness of innovators lies in openness to novelties, curiosity about new technologies and the early awareness of new products/technologies. This adopter category was considered not to be price-sensitive, but cosmopolite, highly educated and more interested in novelties [35]. The technological features (i.e. including gaming) of smartphones are essential for representatives of the cluster. Previous studies have already proven the interest of innovators as well as early adopters in new functions and features [48]. Also, the innovators' category is known to be less represented adopter category [35], [63] even in the smartphone market [48] which strengthens the assumption. According to the results, $14.5 \%$ of all respondents are innovators. It is a significantly high number in comparison with the numbers offered by Rogers.

'Early adopters' are an influential part of the society [64] and the users of new technologies included in this group are also well-educated as innovators, however, early adopters would purchase and use the device in order to keep their esteem among the others [35]. More than eighteen percent of the respondents were early adopters according to the result of survey while the results are higher in comparison with Rogers' results. PDA which includes social media apps, e-mail, and office applications is essential for the representatives of the group. Early adopters to some degree are also aware of smartphone innovative technical features [48]. Relative advantage is essential for them from a different point of view. As the early adopters are almost among the first buyers of the product, it is not logical to discuss brand, prestige, design and so on. Afterward, relative advantage indicators become more essential.

'Early majority' is regarded as followers of innovators and early adopters. The early majority always choose to be somewhere in the middle, neither in the beginning nor at the end [35]. Additionally, the adopters consist of almost one-third of the population [35], [41]. According to the result of this study, $22.7 \%$ of respondents might be considered as early adopters' cluster. Smartphone's technical features, camera usage, and cellular/mobile phone functions are important for the cluster members while the relative advantage is influential only to some extent.

'Late Majority' usually consists of the other one-third of the population [35], [63] and this group of buyers/users is suspicious about novelties [48]. The group adopts the new technologies after novelty became mainstream in society [35], [64]. More than 
$26 \%$ of the respondents match the characteristics of a late majority category the most. Technical Features and Relative Advantage are not essential in the case of the referred adopter category. The results of the survey show that smartphone users belonging to this group use smartphone as a combination of PDA, communication tool (i.e. phone calls and messages) and games.

'Laggards' is the last innovation adoption category which can be characterized by having a more traditional mindset [35], [48]. Laggards and Late Majority may be accepted to be the slowest smartphone adopting categories [65, p. 49]. The group also called laggards usually adopts an innovative product as a result of economic/social necessity. The cluster that showed laggards was chosen according to the Relative Advantage (i.e. with high probability the handset price). The Relative Advantage indicator was the only indicator with a positive value and all other five principal components had a negative value. Interestingly, almost $18 \%$ of the respondents fall into this category.

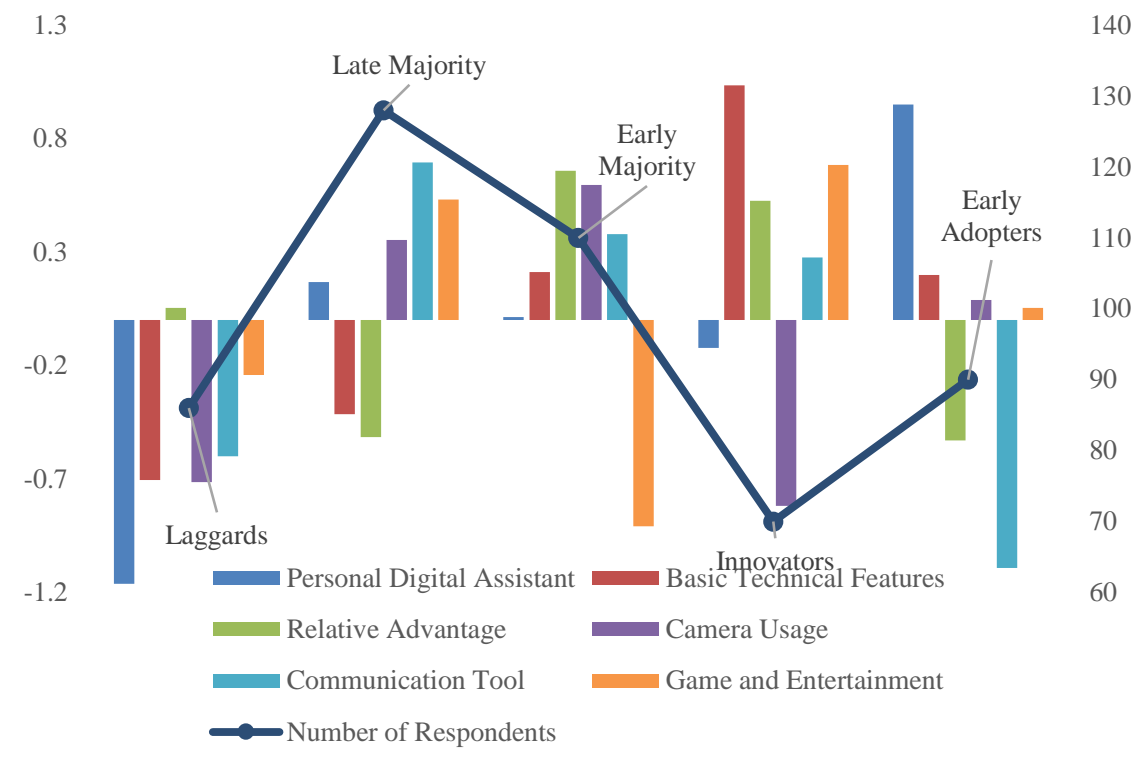

Fig. 2. Final Cluster Centres and Number of Respondents in Each Cluster

Note: The percentages of the adopter categories of the study were summarized as follows:

Innovators (the 4th cluster) - 14.5\%; Early adopters (the 5th cluster) - 18.6\%; Early majority (the 3rd cluster) $-22.7 \%$; Late majority (the 2 nd cluster) $-26,4 \%$; Laggards (the 1 st cluster) $-17.8 \%$;

According to the results of the current paper, innovators and early adopters showed higher numbers in comparison with prior studies [35], [66]. The big proportion of respondents are young individuals (less than 35 years old) which might be the reason for these large numbers. Also, more than $75 \%$ of respondents have a university degree and it increases their probability to be innovators and early adopters [35]. By contrast, early and late majority showed low numbers in comparison with Rogers' adopter categories 
[35] and Bass Diffusion Model [66]. Laggards are a bit more than the number offered by Rogers [35], however, they are in the range offered by Bass [66].

Table 4. The review of the theoretical and the practical results of IDT

\begin{tabular}{|l|c|c|c|c|c|}
\hline $\begin{array}{c}\text { Theoretical/ } \\
\text { practical } \\
\text { results Adopter } \\
\text { category }\end{array}$ & $\begin{array}{c}\text { Rogers IDT } \\
\text { [34, p. 324] }\end{array}$ & $\begin{array}{c}\text { Bass Diffusion } \\
\text { Model [65] }\end{array}$ & $\begin{array}{c}\text { Use of } \\
\text { smartphone for } \\
\text { travel [47] }\end{array}$ & $\begin{array}{c}\text { Mobile technol- } \\
\text { ogy and } \\
\text { smartphone app } \\
\text { [36] }\end{array}$ & $\begin{array}{c}\text { Results of the } \\
\text { current re- } \\
\text { search }\end{array}$ \\
\hline Innovators & $2.5 \%$ & $0.2 \%$ to $2.8 \% *$ & $6.6 \%$ & $10.06 \%$ & $14.5 \%$ \\
\hline Early Adopters & $13.5 \%$ & $9.5 \%$ to $20 \%$ & $28 \%$ & $39.24 \%$ & $18.6 \%$ \\
\hline Early Majority & $34 \%$ & $29.1 \%$ to 32.1\% & $26.3 \%$ & $37.02 \%$ & $22.7 \%$ \\
\hline Late Majority & $34 \%$ & $29.1 \%$ to 32.1\% & $30.3 \%$ & $7.44 \%$ & $26,4 \%$ \\
\hline Laggards & $16 \%$ & $21.4 \%$ to $23.5 \%$ & $8.9 \%$ & $6.24 \%$ & $17.8 \%$ \\
\hline
\end{tabular}

Note: *included to overall \% of Early Adopters

Source: own editing based on literature review.

\section{Conclusion}

Nowadays, in order to attract buyers, each company in the smartphone market tries to introduce the device which contains innovations. It is the best way to market devices in the telecommunication industry. According to the result of the above-mentioned analysis for the Azerbaijani and the Hungarian as well as some international smartphone users are more interested in PDA and Technical Features of smartphones more than the price and other Relative Advantage indicators. The comparison of several studies showed that Personal Digital Assistant (i.e. business/job-related functions and social media) and Technical Features are essential for smartphone/mobile phone buyers/owners from any part of the world. The price of smartphone influences the purchase decision while none of the studies [15], [16] including current one proved its essential place or essential weight in the component. Interestingly, after PDA and Technical Features, buyers from any part of the world pay more attention to the brand and physical characteristics/aesthetics of the handsets. The basic function of smartphones (phone calls and text messages) as a communication tool explains only $6.8 \%$ of the total variance. While it is interesting that all Relative Advantage (i.e. the combination of brand, prestige, innovativeness, design, and price) indicators move together in the Principal Component Analysis and created one group. Moreover, playing games or gaming features is the last factor which influences buyers' purchase decision.

The results of the research illustrated that, even from a product-based perspective, it is possible to identify adopter categories. In order to do the latter, the authors did not ask survey participants about their personality characteristics. Dividing respondents into 5 clusters and illustrating cluster centers was enough in the case of smartphones. Technological features together with Relative Advantage indicators involved from Rogers' book [35] and detailed descriptions of adopter categories eased the task. As the number of young respondents is high enough (i.e. $77.4 \%$ of respondents were 18-34 years old), logically, the number of innovators and early adopters in the current sample 
was above the range proposed by Rogers. Meanwhile, the early and late majority were less represented in the sample.

The limitations of the study are connected with the exploratory characteristics and survey participants. Firstly, the respondents of the survey can be considered to be young, however, it expresses the importance of understanding the purchase intentions and attitudes of the youngest generations. On the other side, it can be considered as one of the serious limitations. Secondly, the survey had self-reporting characteristics, where answers did not reflect the real opinion of users and tried to remain socially accepted. Also, the survey was conducted in different countries (i.e. Azerbaijan and Hungary) and the results were analyzed together while the attitudes, economic/social conditions and culture of smartphone buyers/users are different. Future researches will be focused on analyzing attitudes, behavioral intention, and purchase behavior of smartphone users separately in both of the countries, to find out differences.

\section{References}

[1] R. Earnshaw and J. Vince, Digital convergence-libraries of the future. Springer-Verlag London, 2008.

[2] J.-P. Tsai and C.-F. Ho, "Does design matter? Affordance perspective on smartphone usage," Ind. Manag. Data Syst., vol. 113, no. 9, pp. 1248-1269, 2013. https://doi.org/10.1108/imds-04-2013-0168

[3] C. Giachetti and G. Marchi, "Evolution of firms' product strategy over the life cycle of technology-based industries: A case study of the global mobile phone industry, 1980-2009," Bus. Hist., vol. 52, no. 7, pp. 1123-1150, 2010. https://doi.org/10.1080/ $\underline{00076791.2010 .523464}$

[4] D. C. Coelho, R. F. C. Meneses, and M. R. A. Moreira, "Factors influencing purchase intention of private label products: The case of smartphones," Int. Conf. Explor. Serv. Sci., pp. 313-321, 2013.

[5] S. Toufani, J. P. Stanton, and T. Chikweche, "The importance of aesthetics on customers' intentions to purchase smartphones," Mark. Intell. Plan., vol. 35, no. 3, pp. 316-338, 2017. https://doi.org/10.1108/mip-12-2015-0230

[6] A. Salmi and E. Sharafutdinova, "Culture and design in emerging markets: The case of mobile phones in Russia," J. Bus. Ind. Mark., vol. 23, no. 6, pp. 384-394, 2008. https://doi.org/10.1108/08858620810894436

[7] M. K. Kim, S. F. Wong, Y. Chang, and J. H. Park, "Determinants of customer loyalty in the Korean smartphone market: Moderating effects of usage characteristics," Telemat. Informatics, vol. 33, no. 4, pp. 936-949, 2016. https://doi.org/10.1016/j.tele.2016. $\underline{02.006}$

[8] B. Baah and N. Naghavi, "Beyond the basics: How smartphones will drive future opportunities for the mobile money industry," 2018.

[9] S. Sam, "Bridging the Digital Gap in Sub-Saharan Africa," in Mapping Digital Divide in Africa, M. Ragnedda and B. Mutsvairo, Eds. Amsterdam University Press, 2019, pp. 215256. https://doi.org/10.1515/9789048538225-013

[10] H. A. B. Elammari and N. Cavus, "Investigating the Factors Affecting Students' Smartphone Purchasing Behaviors in the Context of Mobile Learning," Int. J. Emerg. Technol. Learn., vol. 14, no. 22, pp. 111-121, 2019. https://doi.org/10.3991/ijet. $\underline{\mathrm{v} 14 \mathrm{i} 22.11748}$ 
[11] C. Giachetti, Competitive dynamics in the mobile phone industry, 1st ed. 2013.

[12] W. Z. Khan, Y. Xiang, M. Y. Aalsalem, and Q. Arshad, "Mobile phone sensing systems: A survey," IEEE Commun. Surv. Tutorials, vol. 15, no. 1, pp. 402-427, 2013. https://doi.org/10.1109/surv.2012.031412.00077

[13] C. M. Chen, H.-M. Liu, and B.-Y. Ann, "Product Attributes and Purchase Intention for Smartphones: A Moderated Mediation Model," Int. J. Mob. Commun., vol. 16, no. 1, pp. 123, 2018. https://doi.org/10.1504/ijmc.2018.088270

[14] S. Y. Lee, "Examining the factors that influence early adopters' smartphone adoption: The case of college students," Telemat. Informatics, vol. 31, no. 2, pp. 308-318, 2014. https://doi.org/10.1016/j.tele.2013.06.001

[15] G. Işiklar and G. Büyüközkan, "Using a multi-criteria decision-making approach to evaluate mobile phone alternatives," Comput. Stand. Interfaces, vol. 29, no. 2, pp. 265-274, 2007. https://doi.org/10.1016/j.csi.2006.05.002

[16] M. Haverila, "Mobile phone feature preferences, customer satisfaction and repurchase intent among male users," Australas. Mark. J., vol. 19, no. 4, pp. 238-246, 2011. https://doi.org/10.1016/j.ausmj.2011.05.009

[17] L. Petruzzellis, "Mobile phone choice: Technology versus marketing. The brand effect in the Italian market," Eur. J. Mark., vol. 44, no. 5, pp. 610-634, 2010. https://doi.org/10.1108/03090561011032298

[18] H. Chun, H. Lee, and D. Kim, "The Integrated Model of Smartphone Adoption: Hedonic and Utilitarian Value Perceptions of Smartphones Among Korean College Students," Cyberpsychology, Behav. Soc. Netw., vol. 15, no. 9, pp. 473-479, 2012. https://doi.org/10.1089/cyber.2012.0140

[19] M.-H. Hsiao and L.-C. Chen, "Smart phone demand: An empirical study on the relationships between phone handset, Internet access and mobile services," Telemat. Informatics, vol. 32, no. 1, pp. 158-168, 2015. https://doi.org/10.1016/j.tele.2014.06.001

[20] M. Jamalova and M. Constantinovits, "The Comparative Study of the Relationship Between Smartphone Choice and Socio-Economic Indicators," Int. J. Mark. Stud., vol. 11, no. 3, p. 11, 2019.

[21] M. Sata, "Factors Affecting Consumer Buying Behavior of Mobile Phone Devices," Mediterr. J. Soc. Sci., vol. 4, no. 12, pp. 103-112, 2013.

[22] N. Shabrin, S. Khandaker, S. Bin, A. Kashem, C. K. Hie, and T. Susila, "Factors Affecting Smartphone Purchase Decisions of Generation-Y," J. Contemp. Issues Bus. Gov., vol. 23, no. 1, pp. 47-65, 2017.

[23] C. P. Haugtvedt, P. M. Herr, and F. R. Kardes, Eds., Handbook of consumer psychology. Taylor \& Francis Group/Lawrence Erlbaum Associates, 2008.

[24] W. D. Crano, R. Prislin, and (Eds), Attitude and Attitude Change. New York: Psychology Press, 2008.

[25] M. J. Caballero and P. J. Solomon, "Effects of model attractiveness on sales response," J. Advert., vol. 13, no. 1, pp. 17-33, 1984.

[26] J. S. Kim, "An Investigation of Key Factors Affecting the Adoption of Smartphone in Three Regions," Int. J. Innov. Technol. Manag., vol. 13, no. 06, p. 1640017, 2016. https://doi.org/10.1142/s0219877016400174

[27] N. Mohd Suki, "Students' demand for smartphones," Campus-Wide Inf. Syst., vol. 30, no. 4, pp. 236-248, 2013. https://doi.org/10.1108/cwis-03-2013-0013

[28] R. Filieri and Z. Lin, "The role of aesthetic, cultural, utilitarian and branding factors in young Chinese consumers' repurchase intention of smartphone brands," Comput. Human Behav., vol. 67, pp. 139-150, 2017. https://doi.org/10.1016/i.chb.2016.09.057 
[29] M. J. Haverila, "Market segmentation in the cell phone market among adolescents and young adults," Asia Pacific J. Mark. Logist., vol. 25, no. 3, pp. 346-368, 2013. https://doi.org/10.1108/apjml-07-2012-0064

[30] N. Liu and R. Yu, "Identifying design feature factors critical to acceptance and usage behavior of smartphones," Comput. Human Behav., vol. 70, pp. 131-142, 2017. https://doi.org/10.1016/j.chb.2016.12.073

[31] G. Cecere, N. Corrocher, and R. D. Battaglia, "Innovation and competition in the smartphone industry: Is there a dominant design?” Telecomm. Policy, vol. 39, pp. 162-175, 2015. https://doi.org/10.1016/j.telpol.2014.07.002

[32] C. Peechapol, J. Na-Songkhla, S. Sujiva, and A. Luangsodsai, "Development of smartphone application based on the theory of planned behaviour to enhance self-efficacy for online learning," Int. J. Interact. Mob. Technol., vol. 12, no. 4, pp. 135-151, 2018. https://doi.org/10.3991/ijim.v12i4.8715

[33] N. Katuk, N. H. Zakaria, and K. R. Ku-Mahamud, "Mobile phone sensing using the built-in camera," Int. J. Interact. Mob. Technol., vol. 13, no. 2, pp. 102-114, 2019. https://doi.org/10.3991/ijim.v13i02.10166

[34] N. Ameen and R. Willis, "Towards closing the gender gap in Iraq: understanding gender differences in smartphone adoption and use," Inf. Technol. Dev., vol. 1102, pp. 1-26, 2018. https://doi.org/10.1080/02681102.2018.1454877

[35] E. M. Rogers, The diffusion of innovation, 5th ed. New York: Free Press, 2003.

[36] Y. Truong, R. R. Klink, G. Simmons, A. Grinstein, and M. Palmer, "Branding strategies for high-technology products: The effects of consumer and product innovativeness," J. Bus. Res., vol. 70, pp. 85-91, 2017. https://doi.org/10.1016/j.jbusres.2016.07.003

[37] R. C. Nickerson, M. Austreich, and J. Eng, "Mobile technology and smartphone apps: A diffusion of innovations analysis," in 20th Americas Conference on Information Systems, AMCIS 2014, 2014, pp. 1-12.

[38] V. Mahajan, "Innovation diffusion," Wiley International Encyclopedia of Marketing (Part 1. Marketing Strategy). Wiley Online Library, 2010. https://doi.org/10.1002/ 9781444316568.wiem01026

[39] G. Roach, "Consumer perceptions of mobile phone marketing: A direct marketing innovation,” Direct Mark., vol. 3, no. 2, pp. 124-138, 2009. https://doi.org/10.1108/1750593091 $\underline{0964786}$

[40] R. Peres, E. Muller, and V. Mahajan, "Innovation diffusion and new product growth models: A critical review and research directions," Int. J. Res. Mark., vol. 27, no. 2, pp. 91-106, 2010. https://doi.org/10.1016/j.ijresmar.2009.12.012

[41] V. Mahajan, E. Muller, and F. M. Bass, "New-product diffusion models," Handbooks Oper. Res. Manag. Sci., vol. 5, pp. 349-408, 1993. https://doi.org/10.1016/s0927-0507(05)80031$\underline{3}$

[42] C. Stummer, E. Kiesling, M. Günther, and R. Vetschera, "Innovation diffusion of repeat purchase products in a competitive market: An agent-based simulation approach," Eur. J. Oper. Res., vol. 245, no. 1, pp. 157-167, 2015. https://doi.org/10.1016/j.ejor.2015. 03.008

[43] W. A. Kamakura and S. K. Balasubramanian, "Long-term forecasting with innovation diffusion models: The impact of replacement purchases," J. Forecast., vol. 6, no. 1, pp. 1-19, 1987. https://doi.org/10.1002/for.3980060102

[44] E. M. Rogers, Diffusion of innovations, 3rd ed. The Free Press, 1983.

[45] F. M. Bass, "A new product growth for model consumer durables," Manage. Sci., vol. 15, no. 5, pp. 215-227, 1969. 
[46] D. Kim, H. Chun, and H. Lee, "Determining the Factors that Influence College Students' Adoption,” J. Assoc. Inf. Sci. Technol., vol. 65, no. 3, pp. 578-588, 2014.

[47] D. Kim, D. Rueckert, D. Kim, and D. Seo, "Students' Perceptions and Experiences of Mobile Learning," Lang. Learn. Technol., vol. 17, no. 3, pp. 52-73, 2013.

[48] B. Meng, M. H. Kim, and Y. H. Hwang, "Users and Non-users of Smartphones for Travel: Differences in Factors Influencing the Adoption Decision," Asia Pacific J. Tour. Res., vol. 20, no. 10, pp. 1094-1110, 2015. https://doi.org/10.1080/10941665.2014.95 $\underline{8508}$

[49] S. Vinogradov, "A versenyképesség puha tényezői számbavételének módszertani kérdései," in A versenyképesség-mérés változásai és új irányai, C.-C. Csath, M; Taksás, B; Nagy, B; Vinogradov, Sz; Pálfi, N; Fási, Ed. Budapest: Dialóg Campus Kiadó-Nordex Kft, 2019, pp. 121-136.

[50] A. Gazley, A. Hunt, and L. McLaren, "The effects of location-based-services on consumer purchase intention at point of purchase," Eur. J. Mark., vol. 49, no. 9/10, pp. 1686-1708, 2015. https://doi.org/10.1108/ejm-01-2014-0012

[51] . Stoica, C. Vegheş, and M. Orzan, "Statistical Exploratory Marketing Research on Romanian Consumer's Behavior Regarding Smartphones," Procedia Econ. Financ., vol. 32, no. 15, pp. 923-931, 2015. https://doi.org/10.1016/s2212-5671(15)01549-x

[52] A. Field, discovering statistics using IBM SPSS statistics, 4th ed. SAGE Publications Ltd, 2013.

[53] J. F. J. Hair, W. C. Black, B. J. B. Rolph, and R. E. Anderson, Multivariate Data Analysis, 7th ed. Pearson Education Limited, 2013.

[54] B. G. Tabachnick and L. S. Fidell, Using Multivariate Statistics, 6th ed. Pearson, 2013.

[55] D. George and P. Mallery, IBM SPSS statistics 23 step by step: A simple guide and reference. Routledge, 2016. https://doi.org/10.4324/9780429056765-3

[56] L. Puspitasari and K. Ishii, "Digital divides and mobile Internet in Indonesia: Impact of smartphones," Telemat. Informatics, vol. 33, no. 2, pp. 472-483, 2016. https://doi.org/10.1016/j.tele.2015.11.001

[57] C. H. Liao and I. Y. Hsieh, "Determinants of Consumer's Willingness to Purchase GrayMarket Smartphones," J. Bus. Ethics, vol. 114, no. 3, pp. 409-424, 2013. https://doi.org/10.1007/s10551-012-1358-7

[58] I. Li, R. Simonson, G. Babajanova, and M. Tuomala, "Smartphone diffusion and consumer price comparison shopping behavior: Implications for the marketplace fairness act," Econ. Bull., vol. 36, no. 3, pp. 1337-1353, 2016.

[59] T.-P. Liang, C.-Y. Lai, P.-H. Hsu, and C.-M. Chiu, "Factors Affecting Satisfaction and Brand Loyalty to Smartphone Systems: A Perceived Benefits Perspective," Int. J. Mob. Commun., vol. 16, no. 5, pp. 513-533, 2018. https://doi.org/10.1504/ijmc.2018. $\underline{094353}$

[60] C. H. Yeh, Y. S. Wang, and K. Yieh, "Predicting smartphone brand loyalty: Consumer value and consumer-brand identification perspectives," Int. J. Inf. Manage., vol. 36, no. 3, pp. 245257, 2016. https://doi.org/10.1016/j.ijinfomgt.2015.11.013

[61] C. Song and K. Lee, The Samsung way: Transformational management strategies from the world leader in innovation and design. McGraw-Hill Education New York, NY, 2014.

[62] B. S. Everitt, S. Landau, M. Leese, and D. Stahl, Cluster Analysis, 5th ed. West Sussex: John Wiley \& Sons Ltd, 2011.

[63] B. Libai, V. Mahajan, and E. Muller, "Can you see the chasm? Innovation diffusion according to Rogers, Bass, and Moore," Rev. Mark. Res., vol. 5, pp. 38-57, 2009. https://doi.org/10.4324/9781351550901-2 
[64] E. M. Rogers, "Diffusion of Innovations: Modifications of a Model for Telecommunications," in Die Diffusion von Innovationen in der Telekommunikation, 1995, pp. 25-38.

[65] A. J. Reid, Smartphone Paradox. Springer, 2018. https://doi.org/10.1007/978-3-642-79868$\underline{9} 2$

[66] V. Mahajan, E. Muller, and R. K. Srivastava, "Determination of Adopter Categories by Using Innovation Diffusion Models,” J. Mark. Res., vol. 27, no. 1, p. 37, 1990.

\section{$7 \quad$ Authors}

Maral Jamalova is $\mathrm{Ph}$. D. Candidate in Szent István University, Hungary. Her research interest is difference of purchase and usage behavior in smartphone market in developed and developing countries. E-mail: mjamalova@hotmail.com

Dr. Habil. Milán György Constantinovits is currently an Associate Professor in the Institute of Economics, Law, and Methodology at Szent István University, Hungary. His main research interest is related to intercultural marketing and international trade. E-mail: Constantinovits.Milan@gtk.szie.hu

Article submitted 2020-01-08. Resubmitted 2020-02-18. Final acceptance 2020-02-20. Final version published as submitted by the authors. 